\title{
El acuerdo de mediación: técnica y garantía
}

\author{
The mediation agreement: technique and \\ guarantee \\ o acordo de mediação: técnica e garantia \\ L'accord de médiation: technique et garantie \\ 调解协议:技术和保证
}

\section{Niurka Fournier Duharte ${ }^{1}$ Universidad de Oriente - Cuba}

Revista Derechos en Acción ISSN 2525-1678/ e-ISSN 2525-1686

Año 5/N 15, Otoño 2020 (21 marzo a 20 junio), 123-135

DOI: https://doi.org/10.24215/25251678e394

Recibido: 01/03/2020

Aprobado: 15/04/2020

Resumen: Teniendo como fundamento el Reglamento de Mediación de la Corte Cubana de Arbitraje Comercial Internacional de la República de Cuba, la autora se detiene en analizar las diferencias conceptuales que tienen el compromiso de mediación, el acuerdo previo conjunto y el acuerdo de mediación; explica los elementos formales que a su decir han de cumplimentarse para logarlo y las exigencias en su redacción, como antesala de la efectiva posterior ejecución.

Palabras clave: mediación comercial, elementos formales, acuerdo, ejecución.

Abstract: The international comercial arbitration with his Republic of Cuba,the planner when he is confined expected the driver set and the

\footnotetext{
1 Jueza profesional Titular de la sala de lo Económico del Tribunal Provincial Popular de Santiago de Cuba con 33 años de labor profesional. Vicepresidenta de la Sociedad Científica de Derecho Económico y Financiero de la Unión Nacional de Juristas de Cuba y Profesora Auxiliar de la Facultad de Derecho de la Universidad de Oriente. (ORCID 0000-0001-9708-6573).
} 
agreement with mediation in assaying the at his conceptual discrepancies that have the obligation of and mediation the agreement ;explains in the formal elements to him say, they must be served to get it and the requeriments in his editing, as effective anteroom of her subsequent execution.

Keywords: comercial mediation, formal elements, agreement, and execution.

Resumo: Tendo como fundamento o Regulamento de Mediação do Tribunal Cubano de Arbitragem Comercial Internacional da República de Cuba, a autora se detém em analisar as diferenças conceituais entre o compromisso de mediação, 0 acordo prévio conjunto e 0 acordo de mediação; explica os elementos formais que em sua opinião devem ser cumpridos para alcançá-lo e os requisitos em sua redação, como prelúdio da efetiva execução subsequente.

Palavras-chave: mediação comercial, elementos formais, concordância, execução.

Résumé: Sur la base du règlement de médiation de la Cour cubaine d'arbitrage commercial international de la République de Cuba, I'auteure analyse les différences conceptuelles entre l'engagement de médiation, l'accord préalable conjoint et l'accord de médiation. Et elle explique les éléments formels qui doivent être complétés à cette fin, ainsi que les exigences de sa rédaction, avant l'exécution effective ultérieure.

Mot-clés: médiation commerciale, éléments formels, accord, exécution

摘要: 根据古巴共和国古巴国际商事仲裁法院的调解规则, 作者停止 分析调解承诺，共同在先协议和调解协议之间的概念差异; 它解释了 他认为必须达到的正式要素, 以实现该要求以及其起草要求, 以作为 有效后续执行的序幕

关键词: 商业调解,形式要素,协议, 执行

\section{Nota inicial}

Se trae a examen un elemento, que por formal, su ejercicio requiere de depurada técnica; el acuerdo de mediación, fiel manifestación de voluntad y satisfacción de los mediados, el cual da por sentado la culminación del conflicto. 
Se particularizarán las diferencias del compromiso de mediación, el acuerdo previo y el acuerdo de mediación. Lo importante que resultan las facultades de los mediados, en particular los representantes, para negociar, convenir y comprometer la ejecución del acuerdo alcanzado; unido a la preparación y el sabio desempeño del mediador en su concreción; máxime cuando su calidad propiciará en el mejor de los casos, el efectivo cumplimiento voluntario de dicho concierto o por el contrario la solicitud de su ejecución.

Esta nota, más que todo, emplaza a cumplir con mesura los requerimientos que conllevan al acuerdo, a través de una alternativa pacificadora de solución de conflictos, la mediación comercial.

\section{Del consenso al acto resolutorio}

Entre las renovadoras pautas incorporadas al Decreto-Ley No. 250 "De la Corte Cubana de Arbitraje Comercial Internacional", de 30 de julio de $2007,{ }^{2}$ se encuentra la institucionalización de la prestación de los servicios de mediación a las personas naturales y jurídicas ante conflictos de naturaleza comercial que así lo interesaran, quedando con posterioridad pautado a través de la Resolución número 21 de $2015^{3}$.

Con la experiencia acumulada del ejercicio de este método auto compositivo de gestión de conflictos, para la Corte Cubana se hizo necesario rediseñar y actualizar su instrumentación, con una disposición normativa garante de principios y preceptivas formalidades, que han de cumplir tanto el mediador como los mediados para el logro de la solución de la controversia comercial internacional, siendo la Resolución número 9 del 16 de abril 2018 Reglamento de Mediación de la Corte Cubana de

\footnotetext{
2 En lo adelante "La Corte".

3 Reglamento de Mediación de la Corte Cubana de Arbitraje Comercial Internacional" de fecha 16 de septiembre de 2015.
} 
Arbitraje Comercial Internacional de la República de Cuba su actual normativa. ${ }^{4}$

Dicho Reglamento establece, con carácter voluntario, los servicios de mediación comercial, y a este fin, La Corte dispone de un listado de especialistas, de elevada calificación profesional, habilitados como Mediadores, quienes tienen a su cargo la prestación de este servicio.

Teniendo por sentado la definición que el Reglamento hace de la mediación, como el proceso de carácter auto compositivo, en el cual un mediador ayuda a los mediados en conflicto de carácter comercial a lograr un acuerdo mutuamente aceptable, facilitando su negociación; en su ejercicio han de primar los principios de: voluntariedad, balance de poder, flexibilidad, oralidad, confidencialidad, celeridad ,economía procesal, equidad,legalidad, trato justo y equitativo, buena fe ,disponibilidad, consentimiento informado, intervención mínima e imparcialidad. ${ }^{5}$

Cierto es, que como cualquier conflicto, el proceso de mediación estará permeado de contradicciones, sin embargo, puede darse el caso de que las partes antes de acudir a La Corte previeron que cualquier diferencia acudirían a solucionarlo a través

4 Vid: Gaceta Oficial Extraordinaria No. 57 de 3 de octubre de 2018: Resolución No. 9 del 16 días del mes de abril 2018, "Reglamento de Mediación de la Corte Cubana de Arbitraje Comercial Internacional".

5 Ibid. Articulo 4, p.114, Gaceta Oficial Extraordinaria No. 57 de 3 de octubre de 2018.0tros autores como Tomás Prieto la definen desde una perspectiva jurídica es un proceso autocompositivo en el que las partes con la ayuda del mediador intentan llegar a un Acuerdo total o parcial evitando la jurisdicción o el arbitraje, métodos estos heterocompositivos tradicionales, en los que la decisión final queda en manos de un tercero, árbitro o juez. Vid."El Acuerdo de mediación \& El Contrato de mediación". Para Uría Menéndez, el acuerdo de mediación es el contrato por el que las partes solucionan, de manera total o parcial, la controversia sometida a mediación y que, en consecuencia, les permite evitar un pleito (o arbitraje) o poner fin al ya iniciado. No habrá por tanto acuerdo de mediación mientras las partes no hayan manifestado su voluntad común de quedar vinculadas contractualmente (i.e. de quedar ligadas o "atadas" por un vínculo jurídico creador de obligaciones susceptibles de ser exigidas coactivamente).

https://www.amediar.info/el-acuerdo-de-mediacion-contrato-de-mediacion/. Consultado. 2 de noviembre d 2018, hora 2.20pm. 
de esta alternativa pacificadora. Así lo hace notar el Reglamento, al definirlo como el compromiso de mediación, a través del cual los intervinientes de una relación comercial, adoptan el acuerdo de someter a mediación las controversias que se deriven de la interpretación, aplicación o ejecución de un contrato o acuerdo suscrito por estas; pudiendo adoptar la forma de cláusula contractual o constituirse como un acuerdo independiente. ${ }^{6}$

A tales efectos, la existencia de un compromiso de mediación contenido en un contrato, o en documento aparte en conexión con este, se considera de manera independiente de las restantes cláusulas de dicho contrato, y la validez de la cláusula compromisoria o del compromiso de mediación no se afectará por las razones que vayan en contra de la vigencia del contrato. ${ }^{7}$

También puede acontecer, que en una solicitud directa o expresa, una o ambas partes interesen a La Corte recibir el servicio de mediación, siendo reconocido como acuerdo previo conjunto de mediación ${ }^{8}$. Dicho pedimento se presentará por escrito a la Secretaría, y se remitirá copia a la otra persona con la cual mantiene la relación conflictual, o con la cual se requiere

6 Vid. Artículo 3 del Reglamento de Mediación de la Corte Cubana de Arbitraje Comercial Internacional". p.1144. Cuando exista un compromiso o acuerdo previo de presentarse al proceso de mediación, la solicitud contendrá: a) Los nombres, direcciones y números telefónicos, o cualquier otra referencia a los fines de garantizar la necesaria comunicación con las personas involucradas en el conflicto que se pretende mediar. b) Una breve explicación de los hechos que dan lugar al interés en la mediación y, en su caso, las alternativas de solución que se proponen. ) La propuesta o solicitud de designación de uno o varios Mediadores o, en su caso, de las características que deben tener estos, si se designan por la Corte. d) Cualquier acuerdo en relación con el tiempo que debe demorar la mediación o, en su caso, cualquier propuesta al respecto. e) Cualquier acuerdo relativo al lugar de celebración de las sesiones, como del idioma a utilizar. f) Cualquier acuerdo relativo al pago de los servicios de mediación de la Corte.

\section{Artículo 2, p.1144 del Reglamento del 2018.}

8 Esta solicitud en el acta de voluntariedad y confidencialidad suscrita ante la propia Corte contendrá: a) Los nombres, direcciones y números telefónicos o cualquier otra referencia a los fines de garantizar la necesaria comunicación con las personas involucradas en el conflicto que se pretende mediar. b) Una breve explicación de los hechos que dan lugar al interés en la mediación y, en su caso, las alternativas de solución que se proponen. c) La propuesta o solicitud de designación de uno o varios Mediadores, o las características de estos, si se solicita sean designados por la Corte. 
perfeccionar algún tipo de negociación comercial, a fin de que la misma confirme su disposición de iniciar el proceso de mediación, la que deberá dar respuesta de la misma en el término de los diez días naturales posteriores a su recepción. ${ }^{9}$ Transcurrido el plazo indicado, sin que se cuente con respuesta de la parte a la cual se le dio traslado de la solicitud de mediación, o resultando negativa su disposición de someterse voluntariamente a dicho proceso, se archivarán las actuaciones y se informará al solicitante originario. De ser aceptada por la otra parte, se realizará de conformidad el Reglamento. ${ }^{10}$

De lo que deriva que a diferencia del compromiso de mediación y del acuerdo previo conjunto de mediación, el acuerdo de mediación se logra al concluir o como consecuencia del proceso de mediación, pero en todos prevalece la fiel manifestación de voluntad y satisfacción de las partes en llegar al consenso, da por sentado el fin del conflicto y deja sin efecto el proceso arbitral que no se encuentre firme.

\section{Aspectos formales en pos del acuerdo de mediación y su ejecución}

Si su interés es solucionar el conflicto de forma pacífica; ha de pensar en cómo llegar al consenso. Para ello el mediador fomentará el diálogo constructivo, no adversarial; escuchará a las partes, cuidará de crear un ambiente de confianza y seguridad, de manera que, a partir de la comunicación, se propicie el

9 A cuyos efectos el aceptante deberá presentar un escrito a la Secretaría de la Corte, que deberá contener: a) Su disposición de iniciar el proceso de mediación o su rechazo al mismo. b) Una breve explicación de los hechos que dieron lugar al conflicto en cuestión y si acepta las alternativas de solución propuestas o las que en su caso propone. c) Si acepta la propuesta o solicitud de designación de un Mediador realizada por la otra parte solicitante, o si le interesa designar específicamente a otro o, en su caso, a un Co-mediador.

10 La cláusula de mediación de la Corte pudiera contener el siguiente texto: Cualquier discrepancia sobre la interpretación o ejecución del presente contrato, o derivada del mismo, se resolverá de acuerdo con el Reglamento de Mediación de la Corte Cubana de Arbitraje Comercial Internacional, sin perjuicio del derecho de las partes de acudir directamente al procedimiento de Arbitraje, de acuerdo con el Reglamento de la propia Corte. 
acercamiento de las posiciones, en principio opuestas y, cuando sea procedente, dada la naturaleza del asunto, tratará de encaminar el debate hacia una solución que merezca la aceptación común de estas o que ofrezca el mayor beneficio a los intereses objeto de protección, hasta la conveniencia de alcanzar un arreglo entre las partes.

Al mismo tiempo, la mediación no evade al contradictorio; las proposiciones de acuerdo que se realicen por los mediados durante su desarrollo, estarán inmersas en contiendas; solo la sabia y oportuna intervención del mediador y la colaboración de los mediados, propiciarán el diálogo cordial, el cambio y equilibrio de posiciones contrapuestas, el entendimiento y la armonía, hasta conseguir el arreglo.

El mediador, debe ser observador, comunicador, imparcial, ágil, objetivo, perspicaz, intelectivo, generalizador y subjetivo; ha de ser de escucha activo, instintivo, lógico, reflexivo, analítico, persuasivo, táctico, vigilante y asertivo. No debe hacer manifestaciones verbales sobre ninguna de las posiciones, no debe mostrar una conducta pasiva e inmóvil y no debe rebatir las propuestas e inconformidades de una o ambas partes.

Debe dotarse de técnicas y habilidades que le permitan saber estimular el debate, escudriñar pensamientos y manifestaciones que rebasen los límites del respeto; ha de observar e interpretar signos, manifestaciones y gestos; entre otras cualidades que son propias de su gestión.

Al mismo tiempo, se requiere de los mediados: rapidez, sagacidad, destreza, sensibilidad, flexibilidad, respeto, autocontrol, colaboración y buena fe.

Importante resulta la capacidad que le viene atribuida a las partes en el proceso de mediación comercial ante La Corte; los representantes legales y procesales además de ostentar la facultad por su personería, tienen que poseer autoridad y mandato suficiente para llegar a proponer, aceptar y rechazar ofertas; no escondan datos, informes, documentos o razonamientos que limiten la eficacia y beneficio del acuerdo al que tentativamente 
pudiera desarrollarse. De no cumplirse dichos requerimientos, afectará la calidad de la mediación comercial y los actos subsiguientes que se deriven de él.

Los mediados actuarán en el proceso de mediación por sí mismos, o a través de representantes con poder de decisión acerca del fondo del asunto de que trate su controversia. Si el mediado es una persona jurídica, esta se hará representar en las sesiones de mediación por un directivo o ejecutivo de la entidad, con facultades para negociar y acordar una solución del conflicto y comprometer la ejecución del acuerdo alcanzado. En caso de que los mediados interesen representación en el proceso de Mediación, aportarán los nombres y la localización exacta de sus representantes para que sean invitados a la Mediación o podrán ser presentados por ellos mismos.

Los representantes de los mediados deberán ostentar poderes plenos para adoptar acuerdos relativos al fondo del asunto de que se trate, y se demostrará a través de un documento legal habilitante que deberá ser presentado a la Secretaría de la Corte antes de abrirse a proceso la mediación correspondiente.

Aunque los mediados son los responsables del acuerdo a que puedan arribar, éste deberá corresponderse con el ordenamiento jurídico vigente al momento de su adopción, respetando la Ley aplicable al contrato y las disposiciones de orden público de su lugar de ejecución o de la posible ejecución del acuerdo en caso de incumplimiento del mismo. Por ello, independientemente del principio de confidencialidad a cumplir en este proceso, el mediado no deberá ocultar datos o informaciones que repercutan en el éxito y satisfacción del acuerdo; por lo que no podrá responsabilizar al mediador de cualquier omisión que no se le comunicó, salvo que se demuestre negligencia o intencionalidad en su proceder profesional.

Para la materialización del acuerdo se requiere además de otro elemento, que por formal no deja de ser importante: el acta.

La solución del conflicto a la cual arriben los mediados, deberá ser plasmada por escrito en un acta contentiva del Acuerdo 
de Mediación, ${ }^{11}$ ratificando lo aprobado, con la firma de estos y del Mediador.

El acta, es la expresión escrita de todo lo acontecido; en ella se asienta con indicación exacta, clara y concisa: las cuestiones litigiosas mantenidas, a los efectos de que éste continúe en relación a las mismas; los aspectos concordantes a los que arribaron los mediados, incluidos el tiempo y lugar de las obligaciones de dar, de hacer y no hacer pactadas y las personas forzadas al mismo.

El acta, debe: a) precisar, enumerar y suscribir expresamente los aspectos que serán objeto de examen, los puntos controvertidos persistentes en el conflicto subsistente y los términos sobre los que permanecerá la contienda (de ser parcial el acuerdo); b) la precisión de lo acordado, y c) la firma de los participantes con capacidad para ello.

Suele ocurrir que la existencia de diversos puntos controvertidos o varias partes, posibilita que el acuerdo resulte parcial, al resolverse únicamente algunos de los aspectos que han sido objeto del proceso de mediación. Le corresponderá al mediador concretar los asuntos a los que se avienen las partes y a los que no.

Arribar a un acuerdo parcial, requiere del estudio minucioso del mediador, éste además de comprobar la licitud, verificará lo que se llegó a consenso y por lo que continuará la demanda. El mediador no puede irse por encima de lo que las partes disienten o aceptan; en esa relación convenida, su intervención será para, velar porque el acuerdo esté dentro de los marcos legales. Él es objeto de examen por los mediados, y no puede hacer caso omiso a los aspectos latentes en el conflicto, ni a las consideraciones de los intervinientes.

El Reglamento de La Corte cubana se pronuncia porque de no haberse llegado a un acuerdo, se redacte un acta, únicamente

11 Se recuerda que el Acta de Medicación se proclamó por Napoleón Bonaparte el 19 de febrero de 1803 en la Conferencia de Suiza. 
como constancia de conclusión del proceso de mediación, y en tal caso los mediados podrán intentar otra forma de resolución alternativa del conflicto o dirigirse a los tribunales ordinarios. De haberse logrado un acuerdo parcial, los mediados contarán con igual posibilidad, aunque solo en relación a los aspectos sobre los cuales no se logró el acuerdo. Sendos resultados al término de la mediación, obligan al mediador informarlo por escrito a la Secretaría de la Corte, en un plazo no mayor de 20 días hábiles. ${ }^{12}$

La conjunción entre la aptitud del mediador, la voluntad y capacidad de los mediados de llegar a consenso, la depurada técnica del ejercicio de éste método alternativo y la correcta interpretación, redacción y definición de lo acordado, garantizará que, en ningún caso, de no arribar a un acuerdo sea valorado en contra de ninguno de los participantes en el proceso de mediación; las declaraciones realizadas, puedan ser posteriormente alegadas y sostenidas como causa de recusación de los mediadores o como medio probatorio de una parte en contra de la otra.

No se puede soslayar de atención su redacción, el acuerdo ha de cumplir las tres E: equitativo, eficaz y específico y ha de tener en cuenta las adverbios de persona, modo, tiempo y lugar: ¿Quién? ¿Cómo? ¿Cuándo? y ¿Dónde?; de lo contrario, prevalecerá ambigüedad en su texto, propiciará el quebrantamiento de la armonizaciones de los intereses de las partes, la ruptura de las relaciones que prevalecían entre ellos, surgirán conflictos diferentes al conocido y sobre todo conducirá a la inejecución del acuerdo. ${ }^{13}$

Parafraseando a ANDREW FLOYER, el acuerdo ha de ser realista, claro y verificable, y tomará la forma que las partes

\footnotetext{
12 Gaceta Oficial Extraordinaria No. 57 de 3 de octubre de 2018: Resolución No. 9 del 16 días del mes de abril 2018, "Reglamento de Mediación de la Corte Cubana de Arbitraje Comercial Internacional". Artículo 24 inciso 1, p.1148.

13 FOURNIER DUHARTE, Niurka: La conciliación judicial en el procedimiento económico cubano. Tesis en opción al grado científico de Doctora en Ciencias Jurídicas, La Habana , 2013.
} 
decidan, los intereses objetivos y su voluntad. ${ }^{14}$ Por eso, si se quiere garantizar el cumplimiento voluntario del acuerdo, el mediador cuidará porque éste no vaya en contra de las reglas imperativas que rigen en el ordenamiento jurídico y la garantía a los derechos de las partes en sujeción de las disposiciones legales vigentes, y su correcta redacción favorecerá además el cumplimiento voluntario, porque con el tiempo este tiende a mantenerse; pero si alguna de las partes no acata a lo que se sometió, seguro es, que la primera intención tanto del perjudicado como del obligado será el colaborar a favor de su acatamiento.

El acuerdo es susceptible de estar sujeto a circunstancias cambiantes. Puede surgir una afectación que interfiera el cumplimiento exitoso del acuerdo de mediación o variar las condiciones que propiciaron en su día el precitado arreglo. También suele suceder que logrado el acuerdo parcial o durante el proceso arbitral, las partes, logren un nuevo entendimiento o reevaluación de lo acordado o interesen nuevamente los servicios del mediador. Nada se opone, es lícito y viable que los mediados, de común acuerdo, en cualquier momento acudan a la Secretaría de la Corte para modificar los términos en que hubiese firmado el acuerdo alcanzado en la mediación, y aquella se lo informará al mediador que actuó en el caso particular. A tales efectos se redactará una nueva acta de acuerdos de mediación.

Otro elemento del acuerdo de mediación es el poseer carácter definitivo y fuerza vinculante para las partes, las cuales se obligan a su cumplimiento en los términos acordados. En caso de su incumplimiento, su ejecución forzosa puede ser solicitada por la que se considere con derecho a ello, ante los tribunales ordinarios competentes, de conformidad con lo establecido en la Ley. ${ }^{15}$

\footnotetext{
14 FLOYER ACLARD, Andrew. Apud:Quintana García, Amparo: Mediación Mercantil|pdf: http:// www.uria.com/documentos/publicaciones/4481/documento/20150116_um.pdf?id=5651).

15 El artículo 746 inciso g) de la Ley de Procedimiento Civil, Administrativo, Laboral y Económico de Cuba, faculta a las salas de Lo Económico de los tribunales provinciales populares a conocer de las solicitudes que se promuevan para la ejecución de laudos arbitrales, dictados por corte arbitral cubana en el territorio nacional.
} 
Aclara el Reglamento que cuando los acuerdos finales concretados en proceso de mediación internacional hayan de ejecutarse en otro Estado, resulta necesario el cumplimiento de los requisitos establecidos en los Convenios internacionales ratificados por el Estado cubano. Más, en virtud del principio de legalidad, la resolución judicial extranjera contentiva de los acuerdos finales concretados en proceso de mediación internacional no podrá ser reconocida y ejecutada en territorio cubano, cuando resulte manifiestamente contraria al orden público de la República de Cuba.

\section{Ideas Finales}

Por sus efectos la mediación resulta una forma de conclusión de litigios, al tener los mismos requisitos y consecuencias jurídicas que otras alternativas negociadoras.

La preparación técnica de los representantes de las partes, la capacitación de los mediadores, la voluntad de los mediados y la debida calidad en la redacción de lo convenido, coadyuvará al logro de acuerdos efectivos que respondan a los intereses de las partes, la legalidad y el interés general, garantes de su cumplimiento voluntario o por ejecución.

El desempeño consensuado positivo se reconoce en el Laudo el que tendrá autoridad de cosa juzgada y susceptible de interesar la ejecución. La ejecución del acuerdo o su modificación es factible y estará dotado de la flexibilidad característica de la mediación.

Arribado el acuerdo, plasmado en acta y rubricado en Laudo, se archiva el artículo hasta nuevas consideraciones sobre esta alternativa pacificadora de solución de conflictos.

\section{Bibliografía}

CubaLegalInfo (2017). "Decreto-Ley No. 250" de Corte Cubana de Arbitraje Comercial Internacional. La Habana, Cuba. En línea en: http://www.cubalegalinfo.com/mecantil/corte-arbitrajecomercial-internacional/corte-cubana-de-arbitraje 
- (2015) "Resolución Nro. 21 de 16 de Septiembre de 2015 de Corte Cubana de Arbitraje Comercial Internacional. En línea en: http://www.cubalegalinfo.com/mecantil/corte-arbitrajecomercial-internacional/corte-cubana-de-arbitraje

- (2015) "Resolución Nro. 09 de 16 de Septiembre de 2015 de Corte Cubana de Arbitraje Comercial Internacional. En línea en: http://www.cubalegalinfo.com/mecantil/corte-arbitrajecomercial-internacional/corte-cubana-de-arbitraje

- (2015) "Resolución Nro. 21 de 16 de Septiembre de 2015 de Corte Cubana de Arbitraje Comercial Internacional. En línea en: http://www.cubalegalinfo.com/mecantil/corte-arbitrajecomercial-internacional/corte-cubana-de-arbitraje

Fournier Duharte, Niurka (2013). "La conciliación judicial en el procedimiento económico cubano" Tesis en opción al grado científico de Doctora en Ciencias Jurídicas, La Habana . 